\title{
NASA pulls plug on comet collaboration
}

Washington. The United States has pulled out as a major contributor in the European Rosetta mission to visit a comet early in the next century. The move has angered European space scientists, and left participants on both sides dismayed at the sudden breakdown in an international partnership that had been going well.

Wesley Huntress, head of science at the US National Aeronautics and Space Administration (NASA), told Roger Bonnet, his counterpart at the European Space Agency (ESA), at a meeting last month in Washington, that NASA's "funding profile" for the next several years will not allow the agency to deliver the comet lander vehicle it was planning to supply on the schedule that ESA had requested.

Although Rosetta is due to launch in 2003, ESA had asked for the lander - which will separate from the main orbiter spacecraft on arrival at the comet - to be delivered 18 months early. The spacecraft was originally to have carried two landers, one built by Germany (called RoLand), and the other built by Champollion may merge with the German RoLand project. NASA and the French space agency

CNES, called Champollion.

Several months ago, however, ESA decided that weight and budget restrictions for Rosetta, one of the agency's 'cornerstone' science missions, would allow only one lander. That left German, US and French engineers scrambling to combine their two designs into one.

NASA and some US investigators on the Champollion project say that engineering problems alone would make such a merger difficult, if not impossible. The two vehicles had different anchoring systems, and RoLand was designed for a longer stay on the comet's surface.

But others, such as Roger Yelle of Boston University, one of the US investigators on Champollion, believe that issues of politics and ownership have played at least as large a role as the engineering problems. "If the decision-makers in this process wanted to [cooperate], they could do it," he says.

Jean-Pierre Bibring, of the Institut d'Astrophysique Spatiale (IAS) in Paris,

\section{Germany lends Israel helping hand in Brussels}

Munich. Israeli scientists are to benefit from help and advice provided by the German liaison office for the European Commission (KOWI) in their applications to the Commission for research grants under the Fourth Framework programme (FP4). Israel signed an agreement with the European Union at the beginning of August which gives its scientists the right to participate, at their own cost, in all of the framework programmes.

who was the CNES co-project scientist for Champollion, sees NASA's withdrawal as ultimately due to a lack of US interest in keeping the collaboration going. "They did their best not to merge the two [designs] into one," he says.

Some US scientists, however, say that ESA must shoulder part of the blame for the breakdown, having made the original decision to cut back to one lander. ESA also was unable to accommodate NASA's request to deliver Champollion later, they say. Some on the US side point out that NASA is mak-

\section{IMAGE UNAVAILABLE FOR COPYRIGHT REASONS}

ing no such demand for early delivery of the US Cassini mission to Saturn next year.

With the United States out, representatives from ESA, the RoLand project and CNES met last week to assess options for a merged European lander.

Germany, which has been having its own financial difficulties in keeping RoLand afloat, has invited NASA to participate in this reassessment, and engineers at the Jet Propulsion Laboratory (JPL) in Pasadena, California, are still exploring opportunities for US involvement. But few are optimistic that this will come to pass.

NASA, meanwhile, is considering other plans. A study group at JPL is looking at the possibility of flying the cometary science instruments that were to have flown on Champollion on another US lander vehicle, perhaps as a technology test flight under the agency's 'New Millennium' programme.

Jurgen Rahe, NASA's head of planetary exploration, says the planned $\$ 120$-million

Last month, KOWI agreed with Israel's seven universities that it would offer their scientists the same service that it offers to German scientists in helping them to obtain funding from Brussels.

In line with this commitment, KOWI will help Israeli applicants to find their way around the various programmes within FP4, and help them find partners in other European countries, an essential prerequisite for participation. European Huygens probe due to fly on the
US investment in Champollion will still be applied to some kind of comet mission, as NASA continues to regard this as a high scientific priority. Despite many aborted plans in the past 15 years, the United States has yet to launch a spacecraft to study a comet. CNES will be invited to participate in any US mission, says Rahe.

If NASA does fly its own comet mission, what had been a successful international collaboration will turn into a competition. The US spacecraft would launch at around the same time as Rosetta in 2003, but would use

of advanced solar electric propulsion to

岂 reach a still-to-be-determined के cometary target in only three or four

$\frac{\pi}{z}$ years - well ahead of Rosetta's arrival at Comet Wirtanen in 2011.

One problem with the New Millennium option, however, is that this programme is designed primarily to test new spacecraft technologies. Some US scientists fear that research would therefore take a back seat, whereas Champollion was clearly a science-driven mission.

JPL's report on the New Millennium option is due next month, along with decisions on who will be involved in the remaining Rosetta lander.

Officially, ESA and NASA say only that they "regret" the situation, and that this will have no bearing on their relationship. But the affair is likely to put a chill on future space science collaborations - similar to, if not as severe as, the ill-will caused by the US withdrawal from full partnership in the International Solar Polar (now Ulysses) project in the 1980s.

The agencies are already telling different stories about what happened. NASA paints its withdrawal from Champollion as a joint decision between the Europeans and Americans. That has angered some Europeans, who say that CNES was not fully consulted before NASA decided to pull out of the project at the September meeting in Washington. Giacomo Cavallo, Bonnet's deputy in ESA's science directorate, says that while it was a "friendly meeting", it also was "clear it was a NASA decision".

Rahe believes cooperation on the Rosetta mission can still go smoothly. The three US investigators flying experiments on the main orbiting spacecraft should not be affected by the Champollion decision. But Rahe - as well as other space scientists admits that collaboration on spacecraft projects in the era of "better, cheaper, faster" is harder than it used to be.

With more volatile budgets and less flexibility in their schedules, space agencies on both sides of the Atlantic increasingly face the need to change their plans quickly, which makes international consensus much more difficult to achieve. Tony Reichhardt 